\title{
Limitaciones de la planificación territorial departamental, el POTD
}

\section{Limitations of the provincial territorial management, POTD}

\author{
Págs. 31 - 44
}
Grupo de investigación 1: Prospectiva Urbano Territorial
Línea de investigación: Ciudades Competitivas
Tadeo Humberto Sanabria Artunduaga•

\section{RESUMEN}

En Colombia han surgido nuevos instrumentos de planeación territorial: las directrices Departamentales y el Plan de Ordenamiento Territorial Departamental. Por la novedad y por su alcance, se hace algunas limitaciones notables de estos instrumentos para contribuir al propósito de una planificación multinivel y multiescalar en el país. Sobre la base documental revisada, el análisis confronta las competencias de cada nivel de planificación con cuatro funciones de la planeación: la capacidad de intervención frente a la unidad territorial, la intervención en el derecho de propiedad, en el libre mercado y la capacidad de proveer soporte a las actividades territoriales. Los resultados muestran grandes limitaciones para jugar el papel de intermediador de los intereses nacionales y locales, y algunas posibilidades de acción departamental para desarrollar un modelo territorial articulado nacionalmente.

Palabras clave: Plan de Ordenamiento Departamental, directrices departamentales, competencias territoriales, planeación escalar. Instrumentos de planificación.

\begin{abstract}
New tools for spatial planning have emerged in Colombian since the promulgation of the Territory management Act (Ley Orgánica de Ordenamiento Territorial LOOT) in 2011: Departmental Guidelines and Departmental Land Management Plan. This paper focus on how those tackle four territorial challenges: the multiescalar levels of territory from national to local ones, market intervention and property rights, and the capacity to provide territorial support to human activities. The results show some limitations of those to contribute to the purpose of a multi-level and multiscale planning in Colombia and limitations to play the role of intermediary of national and local interests, and some of the possibilities of departmental action to account for a territorial model articulated nationally.
\end{abstract}

Keywords: Departmental Plan land use, departmental guidelines, territorial jurisdiction, multi-scale planning. Spatial Planning instruments.

-Arquitecto. Fundación Universidad de América. Correo electrónico: Tadeo.sanabria@investigadores.uamerica.edu.co 


\section{INTRODUCCIÓN}

La Ley Orgánica de Ordenamiento Territorial (LOOT), en el artículo 29, Ley 1454 del 2011 establece que los departamentos podrán formular directrices y planes de ordenamiento territorial departamental, lo cual abre la posibilidad de una planificación escalar en la política nacional de ordenamiento territorial con base en las competencias de las diferentes entidades e instancias en esta materia.

El presente documento tiene como objeto presentar los resultados del análisis al instrumento por la ley mencionada, realizado en el marco de la línea de investigación Ciudades Competitivas, que lidera el grupo de investigación Prospectiva Urbano Territorial de la Fundación Universidad de América, y en función de los avances en la formulación de los Planes de Ordenamiento Territorial Departamentales (POTD) y de los lineamientos conceptuales y metodológicos que ha propuesto el Departamento Nacional de Planeación y la Comisión de Ordenamiento Territorial (COT) a nivel nacional ${ }^{1}$.

Las directrices son comprendidas como determinantes para lograr el ordenamiento territorial departamental de acuerdo con la visión y modelo de ocupación territorial prospectado ${ }^{2}$. Una vez formuladas las directrices, los municipios deben desarrollarlas en sus Planes de Ordenamiento Departamental, para dar cumplimiento al art. 29 de la LOOT, el cual plantea: "Articular sus políticas, directrices y estrategias de ordenamiento territorial con los planes, programas, proyectos y actuaciones mediante la adopción del Plan de Ordenamiento Territorial Departamental (POTD)". Así el POTD es el instrumento de planificación territorial que permite incidir en el logro de los objetivos de desarrollo departamental.

A pesar de que son varios los departamentos que a instancias de la Ley Orgánica de Ordenamiento Territorial (LOOT) han formulado sus directrices de ordenamiento, hasta la fecha solo hay dos procesos de formulación de Planes de Ordenamiento Departamental (POTD) en marcha. Uno en el departamento del Valle del Cauca y otro en el departamento del Guaviare, que, según el Departamento Nacional de Planeación (DNP), son proyectos piloto que permitirán precisar los alcances de la planeación multiescalar y servir de orientadores tanto en los contenidos como en los procedimientos para el resto de departamentos que inician este proceso.

El documento se ha estructurado de la siguiente manera: primero, dado que se trata de un instrumento de planificación que media la acción de ordenamiento entre el nivel nacional y el nivel local, se hace referencia a los niveles intermedios de la planificación territorial y específicamente a la planeación regional. Y segundo, se alude a las competencias otorgadas por la Constitución a los departamentos y de manera específica a las competencias en materia de ordenamiento territorial.

1 CEI: Comité espacial Interinstitucional de apoyo a la Secretaría Técnica de la COT

2 Entendida la directriz como un conjunto de instrucciones o normas generales para la ejecución y puesta en marcha de cualquier actividad, se definen las Directrices de Ordenamiento Territorial Departamental (POTD) como el marco general de acción para la toma de decisiones en el nivel departamental y municipal con visión prospectiva y de organización del territorio. 
LÍNEA DE INVESTIGACIÓN: CIUDADES COMPETITIVAS

\section{MÉTODOS}

Este análisis se realiza de manera comparada con los otros niveles territoriales, lo que permite revisar los aspectos que estructuran el avance documentado de los lineamientos para la formulación del instrumento denominado Plan de Ordenamiento Departamental (POTD). Un primer análisis, revisa las dificultades que entraña el asumir el papel de intermediación entre el nivel nacional y local, para lo cual se contrasta las funciones que sugiere la teoría de las regiones con las funciones que está en capacidad de asumir el Departamento como entidad territorial.

Como estas capacidades en materia de ordenamiento territorial están ligadas a las competencias conferidas por la Constitución, el análisis del POTD toma en cuenta los documentos de política nacional referidos a los antecedentes, formulación y alcances de este instrumento de planificación, a partir de las competencias asignadas constitucionalmente a cada escala territorial, de la naturaleza de las funciones de planificación y de las aportaciones hechas por los ejercicios de directrices departamentales y los escasos, pero más recientes de ordenamiento departamental.

\section{RESULTADOS. LA REGIÓN REDUCIDA AL DEPARTAMENTO}

Una rápida mirada a las experiencias y referentes de planeación regional puede ilustrar, con varios ejemplos, que los niveles de este tipo planificación están asociados a la organización política de los Estados, lo cual otorga competencias específicas a los distintos entes territoriales que le componen. De acuerdo al papel que juegan en la configuración de un estado particular, cada uno de esos niveles posee ciertas atribuciones que le permiten intervenir en las políticas públicas de ordenamiento territorial y disponer de instrumentos para hacerlas operativas.

En general, los documentos oficiales sobre los planes de ordenamiento departamental consultados equiparan este tipo de ordenamiento al regional. El Instituto Geográfico Agustín Codazzi (IGAC, 2012) y el Ministerio de Vivienda, Ciudad y Territorio (MVCT2012), hacen un interesante recorrido por la planeación regional y las políticas de suelo de algunos países de la Unión Europea para dar soporte a la propuesta conceptual del POTD, y concluyen que la planeación regional pretende garantizar fundamentalmente:

- La localización de las actividades económicas en función del interés general y la localización de servicios y equipamientos en perspectiva del equilibrio regional

- Mecanismos de control para evitar conflictos de usos del suelo, deterioro de recursos naturales o problemas derivados de la densificación urbana

- Sistemas de ciudades, que se configuran mediante una jerarquía de centros (lugares centrales) y sus respectivas áreas de influencia

- Zonificación del grado de desarrollo urbano y delimitación de unidades homogéneas en función de las diferencias socioeconómicas

- Zonificación de las políticas sectoriales con incidencia territorial para indicar usos permitidos, prioritarios o recomendados

- Zonificación de algunas políticas regionales

- Delimitación de ámbitos funcionales 
Sin embargo, en dichos documentos no tienen en cuenta a los mecanismos que han permitido a ese nivel de planificación operar en cada nación y que al no considerarlos, pueda limitar su aplicabilidad en Colombia:

El primero de ellos se refiere a que constitucionalmente en Colombia las atribuciones para regular la ocupación y el uso del suelo son del municipio y el segundo, que considera la localización de las actividades como un proceso orientado por la planificación y no como resultado de un proceso regulado por procesos económicos. De otra parte, al pretender asimilar al departamento como región, obliga a subsumir los criterios y variables que determinan la asociación de los municipios u otras organizaciones territoriales contenidas en su jurisdicción, a unas consideraciones estrictamente administrativas. La evidencia ha mostrado las limitaciones de esta perspectiva (Boix, 2003; Jonas \& Ward, 2007).

Si consideramos que el ordenamiento territorial es un instrumento de la política de Estado que pretende consolidar espacialmente un modelo de desarrollo (Sanabria, 2007), la regionalización es una forma particular de ordenamiento que intermedia la actividad local y global. Un ordenamiento que materializan los agentes económicos y las fuerzas sociales integradas alrededor de un proyecto de desarrollo común en un área que desborda sus nociones locales de territorio. No son sus instituciones las que determinan esa regionalización, estas solo formalizan y apoyan el proceso ofreciendo el soporte político y administrativo.

Con la regionalización surge también una modalidad de planificación centrada en la negociación (Sandoval, 2014), cuyo principal desafío es articular los intereses regionales con los del país, en un proceso de acuerdo político del Estado nacional con cualquier región (Boisier, 2006).

En este punto, es necesario observar especialmente en el ordenamiento territorial, lo que significa el departamento como una entidad territorial que juega el papel de intermediación entre el nivel local y el nacional. A ese respecto muchos analistas, desde la misma promulgación de la Carta Constitucional en 1991 y la consiguiente creación de la COT, coinciden en que el problema institucional más grave del Estado colombiano es la crisis del nivel territorial intermedio. Afirmación que incluso fue esbozada en el CONPES 3238: Estrategias para el Fortalecimiento Departamental (DNP, 2003); donde se señala que la organización de ese nuevo departamento exige que se fortalezca especialmente su papel como intermediador entre el Gobierno nacional y los municipios y como planificador, programador y promotor de desarrollo en su jurisdicción y que se elimine la cláusula general de competencia que en materia administrativa le permite ocuparse de toda clase de funciones y servicios.

En la misma línea, Maldonado (2009) plantea que la crítica situación que han vivido los departamentos ante la implementación del modelo de descentralización es resultado de que el avance que ha tenido el nivel municipal en la definición de competencias, recursos e instrumentos no ha sido similar para los departamentos, y va más allá al indicar que esta entidad enfrenta dificultades para definir el alcance de la función que les fue asignada en la Carta Política en cuanto a la promoción del desarrollo económico y social de su territorio.

Esta limitación de los departamentos se expresaba claramente en el ordenamiento territorial y las políticas de suelo, asumidas casi por completo por los municipios desde la Ley 388/97. El papel que dicha ley asignaba a los departamentos en su artículo séptimo, fue declarado inexequible por la Corte Constitucional y solo fue posteriormente restaurado por la LOOT, que fortalece las competencias para que la Nación formule la política general de ordenamiento territorial como instrumento de planificación, y asigna facultades en esta materia a los departamentos (Massiris, 2010). 
LÍNEA DE INVESTIGACIÓN: CIUDADES COMPETITIVAS

\section{RESULTADOS. LA COMPETENCIA DEL DEPARTAMENTO Y SU CAPACIDAD PARA EL ORDENAMIENTO TERRITORIAL}

Con la LOOT se abrió la posibilidad de una planificación escalar multinivel. Un sistema de planeación cuyo primer nivel corresponde a la Política Nacional de Ordenamiento Territorial (PNOT), la cual ofrecería el marco global de actuación al establecer un modelo general de ocupación del territorio en el largo plazo, un conjunto claro de objetivos y criterios para definir las prioridades y conveniencias en la forma en que la sociedad deberá hacer uso del territorio, y unos temas en los cuales deberá centrar su atención tales como la protección y conservación de las áreas de especial valor ambiental y del patrimonio cultural, el sistema urbano-regional y la adaptación al cambio climático; con lo cual, podrá establecer los propósitos y acciones a implementar en los planes de desarrollo nacional (IGAC, 2012).

Los aprovechamientos de los recursos naturales y de los bienes o servicios construidos socialmente son realizados por los individuos y, en esa medida, estos aprovechamientos establecen la mediación entre el desarrollo social y el ordenamiento territorial (Sanabria, 2012).

Además, el ordenamiento territorial ha de reflejar tanto el esfuerzo individual para desarrollar las propiedades, como el de la cooperación pública y privada para ofrecerle el soporte funcional que lo integre a la ciudad (Moya, 1999). En esa medida, el ordenamiento del territorio ha de garantizar un balance entre la utilidad para el individuo que realiza el aprovechamiento y la utilidad social para el territorio en donde se realiza tal aprovechamiento, a través de un régimen que asegure su ejecución, por cuanto el desarrollo planificado de su propiedad contribuye a concretar los objetivos del plan.

Las anteriores afirmaciones permiten concluir que si bien el ordenamiento del Estado comienza en el nivel nacional, este termina en el nivel de los individuos que son quienes lo materializan. Sin embargo, esta condición del ordenamiento no es suficientemente comprendida en la propuesta de escalamiento de la planeación, ya que allí se considera al municipio como el último nivel del ordenamiento nacional y al departamento como el segundo, al intermediar el nivel nacional y local.

Por lo tanto, el siguiente análisis de escalamiento incorpora cuatro niveles de la planeación territorial: el nivel nacional, el regional -que aquí se centra en el nivel departamental-, el municipal y el individual. El nivel nacional tiene la competencia para determinar restricciones a la ocupación territorial con fuerza de ley; el departamento, intermedia la política nacional de ordenamiento territorial y las actuaciones locales como se ha señalado; el municipal regula el aprovechamiento individual; y los individuos ejecutan el aprovechamiento privado.

Las funciones de la planeación territorial que alimentan el análisis son la unidad del territorio, el régimen de propiedad, la intervención al mercado y la contribución a la creación y mantenimiento de los soportes territoriales (Sandoval, 2014).

La unidad del territorio, por cuanto es la condición de la planeación que permite establecer la contribución de cada nivel a la unidad nacional, más aún cuando el preámbulo de la carta constitucional señala como uno de sus fines 'fortalecer la unidad de la Nación' y en su artículo $1^{\circ}$ determina que Colombia es un Estado social de derecho, organizado en forma de república unitaria, descentralizada y con autonomía de sus entidades territoriales (Constitución Política de Colombia). 
La intervención sobre el régimen de propiedad expresa la capacidad de cada nivel de planeación para ejercer la función pública del urbanismo, garantizando la propiedad privada y su acceso, en desarrollo de los preceptos constitucionales contenidos en los artículos 58, 60, 63, 64, 72 y 332 .

La planeación territorial es considerada una intervención al libre mercado en el sentido de que tiene la capacidad para regular la oferta de suelo e inmobiliaria y la localización e intensidad de las actividades lucrativas y de negocios. En este aspecto se hace una revisión de la competencia y de los instrumentos para esa intervención que tiene cada nivel.

La cuarta función alude a la capacidad de los niveles de planificación para construir y mantener las infraestructuras que soportan la vida social del territorio y las actividades residenciales y productivas que le dan su sentido. Estas infraestructuras que cristalizan las funciones territoriales y facilitan los servicios que requiere la población se concretan en los sistemas estructurantes urbanos. Por tanto el análisis se refiere a la capacidad de cada nivel de planificación para proveer estos sistemas.

Finalmente, dado que la propuesta de la política nacional de ordenamiento es la creación de un sistema de planificación escalar, estas cuatro funciones son sintetizadas en la tabla 1 para cada nivel de escalamiento.

De la tabla 1 se desprenden varias consideraciones con respecto a los departamentos: a la pregunta ¿aplican la norma nacional o sugieren cambios a la ley para adecuarla a las solicitudes locales? La realidad es que la configuración política local tiene en su representación en la Cámara de Representantes un camino directo de comunicación con el legislativo nacional, en tanto el gobernador, como representante del gobierno departamental, es un intermediario de los asuntos de su jurisdicción sin injerencia en los asuntos nacionales. Es, por el contrario, un ejecutor de la política nacional a través de la agenda pactada en su programa de gobierno y bajo la tutela de la nación. En esas condiciones el papel de intermediación entre la nación y los municipios parece darse en una única vía.

Un segundo aspecto sobre el que cabe una reflexión, es que la competencia de la Asamblea Departamental para segregar entidades territoriales dentro de su jurisdicción, derivando o suprimiendo nuevos municipios, proceso que está reglado y muestra una clara autoridad de los departamentos para intervenir en la configuración político administrativa del territorio.

Pero el departamento no tiene capacidad alguna ni instrumentos que le permitan una injerencia sobre dos de las funciones centrales de la planificación territorial: la intervención al derecho de propiedad y la intervención al libre mercado y, de manera específica, sobre el mercado del suelo e inmobiliario. Esta condición deriva en que los planes de ordenamiento territoriales departamentales solo pueden dar recomendaciones sobre estos tópicos al nivel inmediatamente inferior, es decir, a los municipios, que en ejercicio de su autonomía podrán desestimarlas.

Como consecuencia, las capacidades de escalamiento del sistema de planeación territorial nacional se verán menguadas a pesar del señalamiento del MVCT (2012) de que "la autonomía de las entidades territoriales se reducirá cuando se involucre un interés nacional o general claro". Ya que en cualquier caso siempre deberá permitirse la participación de la entidad territorial en la regulación de la materia respectiva. Así pues, las directrices que el departamento genere en ese sentido tales como la localización de ciertos usos, o las disposiciones que se fundamentan sobre calificación y clasificación del suelo, podrán entrar en conflicto con las regulaciones municipales y en este 
LÍNEA DE INVESTIGACIÓN: CIUDADES COMPETITIVAS

caso, tendrían que ser concertadas. Debido a lo anterior, existirá un vacío jurídico para tomar las directrices como determinantes de los planes de ordenamiento territorial municipales con carácter vinculante, como es el sentido otorgado a dichas directrices en los documentos oficiales (IGAC, 2012; DNP, 2012; 2016; MVCT, 2012).

Tabla 1.

Competencias de los niveles de planificación en Colombia

\begin{tabular}{|c|c|c|c|c|}
\hline Factor & Nacional & Departamental & Municipal & Individual \\
\hline $\begin{array}{l}\text { Unidad del } \\
\text { territorio }\end{array}$ & $\begin{array}{l}\text { Define las entidades } \\
\text { territoriales y el marco de } \\
\text { sus competencias }\end{array}$ & $\begin{array}{l}\text { Modifica } \\
\text { jurisdicciones } \\
\text { municipales. } \\
\text { Intermedia. }\end{array}$ & $\begin{array}{l}\text { Organiza el suelo } \\
\text { público y regula el } \\
\text { suelo privado. }\end{array}$ & $\begin{array}{l}\text { Diseña y opera la } \\
\text { ocupación en su } \\
\text { propiedad predial. }\end{array}$ \\
\hline $\begin{array}{l}\text { Régimen de } \\
\text { propiedad }\end{array}$ & $\begin{array}{l}\text { Define dónde no se puede } \\
\text { titular (ej.: zonas protegidas, } \\
\text { subsuelo) } \\
\text { Posee instrumentos para } \\
\text { afectar o extinguir el dominio. }\end{array}$ & No establecido & $\begin{array}{l}\text { Clasifica y califica } \\
\text { el suelo. } \\
\text { Regula el } \\
\text { aprovechamiento }\end{array}$ & $\begin{array}{l}\text { Realiza el } \\
\text { aprovechamiento } \\
\text { de su propiedad. } \\
\text { (explota o edifica) }\end{array}$ \\
\hline $\begin{array}{l}\text { Intervención } \\
\text { al libre } \\
\text { mercado }\end{array}$ & $\begin{array}{l}\text { Determina su legalidad. } \\
\text { Mecanismos de asignación } \\
\text { y redistribución del } \\
\text { aprovechamiento del suelo } \\
\text { y los recursos (minería, } \\
\text { seguridad nacional) }\end{array}$ & No establecido & $\begin{array}{l}\text { Regula el uso } \\
\text { del suelo y sus } \\
\text { intensidades }\end{array}$ & $\begin{array}{l}\text { Dedica su } \\
\text { propiedad a } \\
\text { una empresa. } \\
\text { Propone, gestiona } \\
\text { y ejecuta proyectos } \\
\text { productivos o de } \\
\text { urbanización. }\end{array}$ \\
\hline $\begin{array}{l}\text { Soportes } \\
\text { territoriales }\end{array}$ & $\begin{array}{l}\text { Propone, instrumenta y } \\
\text { ejecuta proyectos motrices: } \\
\text { generación de energía, } \\
\text { seguridad nacional, } \\
\text { movilidad troncal, } \\
\text { macroproyectos, etc. } \\
\text { Define estándares de } \\
\text { soportes urbanos }\end{array}$ & $\begin{array}{l}\text { Propone, gestiona } \\
\text { y ejecuta proyectos } \\
\text { regionales o de } \\
\text { apoyo local como } \\
\text { dispositivos de } \\
\text { tratamiento para } \\
\text { servicios públicos, } \\
\text { equipamiento } \\
\text { regional, manejo de } \\
\text { cuencas. }\end{array}$ & $\begin{array}{l}\text { Propone, gestiona } \\
\text { y ejecuta proyectos } \\
\text { locales (cargas } \\
\text { generales). } \\
\text { Precisa estándares } \\
\text { urbanísticos } \\
\text { (en cargas locales) }\end{array}$ & $\begin{array}{l}\text { Dota } \\
\text { infraestructuras } \\
\text { para operación } \\
\text { privada y suelo } \\
\text { para cargas } \\
\text { locales. }\end{array}$ \\
\hline
\end{tabular}

Nota: Los encabezados se refieren a las entidades territoriales, las columnas, a las funciones centrales de planeación territorial.

Fuente: Elaboración propia.

Con relación a la creación y mantenimiento de soportes territoriales, es la función sobre la cual el departamento ha ejercido tradicionalmente su función de manera articulada con la Nación y con el municipio y donde más claramente son puestos a prueba los principios de coordinación, concurrencia, 
subsidiariedad y solidaridad. Parece claro que la Nación define la política para cada uno de los soportes territoriales, las metas nacionales para alcanzar ciertos estándares de cobertura y calidad con ellos, y desarrolla los proyectos que tienen un carácter estratégico para la nación, tales como los proyectos viales de conexión internacional y las 4G, los proyectos de generación e interconexión de energía, las infraestructuras para garantizar la seguridad nacional, etc. Al municipio, por su parte, le concierne ofrecer el soporte funcional en su jurisdicción, asegurando con suficiencia el suelo que le permita desarrollar los proyectos que configuran los sistemas estructurantes y con su ejecución.

Al departamento le correspondería el desarrollo la infraestructura regional y provincial, especialmente a través de proyectos para la generación, tratamiento y distribución matriz de servicios públicos, equipamiento especializado con cobertura en varios municipios, y las infraestructuras de movilidad intermunicipales o de conexión entre nodos de producción que desbordan las jurisdicciones municipales (Giraldo, 2008). Asimismo, y de la mano con las entidades sectoriales, proyectos que desarrollen iniciativas productivas, los cuales posibiliten la integración de cadenas productivas de varias unidades locales, o permitan desarrollar zonas francas y centros logísticos e industriales. Igualmente le corresponde a este nivel el desarrollo de proyectos de manejo ambiental que desbordan las jurisdicciones municipales, tales como la recuperación o restauración de sistemas ecológicos degradados, las operaciones de protección de la estructura ecológica principal o de mitigación del riesgo (Rivera, 2009). Sin embargo, el consumo de suelo para estos proyectos deberá atenerse a la regulación que los municipios hayan dispuesto sobre el uso del suelo y lo operarán bajo los procedimientos establecidos para cualquier particular, pero de manera concertada y coordinada con aquel.

La competencia en el ordenamiento territorial otorgada al municipio, le permite organizar el suelo público y regular el suelo privado. Es esta entidad territorial la que finalmente determina la política de suelo local y concreta la organización espacial de su territorio, ya que hace la mediación entre el aprovechamiento que ejecutan los agentes privados y los objetivos de desarrollo socioeconómico al que se apuesta localmente de manera articulada con los preceptos de la política nacional. Como se observa, en este proceso parece invisibilizar la función del departamento.

Por lo tanto, el contenido de los Planes de Ordenamiento Departamental se limitaría a proveer recomendaciones y lineamientos al municipio para la organización del suelo público, no del privado; las directrices estarían orientadas a la operación de las cargas generales y no locales, y la intervención sobre los sistemas estructurantes del territorio estaría limitada a los proyectos regionales. No obstante, el departamento, en su papel de mediador de la política nacional y local, tiene el reto de integrar los diferentes planes territoriales y las intervenciones sectoriales.

Este tema entraña varias dificultades. Ya la Secretaría Nacional de Planificación y Desarrollo SENPLADES (2010) plantea que:

"La oferta de intervenciones nacionales se propone desde cada uno de los sectores de la política pública; sin embargo, las demandas territoriales exigen una visión integradora e intersectorial, pues en ese escenario se expresa la complejidad de las relaciones entre los sistemas, subsistemas, componentes y subcomponentes socio-culturales, económicos, ambientales-territoriales y políticoadministrativos." (SENPLADES, 2010, p. 18)

La primera de ellas se refiere a los tiempos de vigencia de los planes de los diferentes niveles de la planificación territorial. La Constitución Nacional da la pauta y ofrece cierta estabilidad a su reglamentación en la política pública nacional de ordenamiento territorial. Sin embargo, los periodos 
LÍNEA DE INVESTIGACIÓN: CIUDADES COMPETITIVAS

constitucionales de la autoridad de gobierno son de cuatro años, en los cuales se ajusta la legislación atendiendo a los intereses del gobierno de turno y así surge un programa de intervención territorial que se inserta en cada plan de desarrollo. Al no contar el país con un plan de intervención territorial de largo plazo, los modelos prospectivos de ocupación nacionales se reducen a una vigencia de cuatro años. Es importante anotar que las actuaciones territoriales de la nación no han requerido de un plan formal de ordenamiento territorial, como tampoco lo ha necesitado el departamento para desarrollar los proyectos de intervención en su jurisdicción antes de la LOOT.

Con la LOOT se da la posibilidad a los departamentos para elaborar este plan. La vigencia prevista en la Propuesta de Acuerdo de la Comisión Nacional de Ordenamiento Territorial COT es de 16 años. O en todo caso, "no menor a 4 periodos constitucionales" (COT, 2016, p. 9).

Las vigencias de largo plazo de los Planes de Ordenamiento Territorial (POTM) son de 12 años y estos planes son ejecutados en tres vigencias constitucionales por los planes de desarrollo municipales correspondientes lo cual establece una articulación entre estos dos instrumentos.

La realización de los aprovechamientos es, como se ha indicado, potestativo de los individuos quienes realizan sobre sus propiedades inversiones por oportunidad, en algunos casos a través de un plan de negocios para garantizar mayores rentas. Esa oportunidad es alentada o desestimulada por las decisiones del Plan de Ordenamiento Territorial Municipal.

Bajo las dispares vigencias en los distintos niveles de la planeación territorial nacional, las posibilidades de la escalaridad de la planeación se reducen. Si partimos de que la base de las vigencias es el POT municipal, las correspondientes al nivel departamental deberían coincidir con múltiplos de aquella, para que siempre existiese un referente superior que determine un modelo territorial al cual cada porción territorial haga su aporte de acuerdo a sus propias peculiaridades; y al mismo tiempo este referente debería permitir su revisión periódica de manera articulada con los otros planes.

Una segunda dificultad alude a la capacidad para incorporar a la formulación del POTD en su función articuladora planes de diversa procedencia y, por consiguiente, para hacer el seguimiento y evaluar el avance y los impactos. Para el caso de los planes de vida de las comunidades indígenas y raizales, la incorporación de sus cosmovisiones al modelo de ocupación del POTD que las integra bajo una concepción occidental, no deja de plantear preguntas de orden conceptual y metodológico, sin respuestas categóricas.

Gran dificultad entraña la armonización de las intervenciones nacionales previstas sobre un departamento con las planeadas por la misma entidad territorial. La suerte de figuras nacionales que limitan la titulación del suelo y que obligan otras formas de tenencia, como los proyectos estructurales que cambian sustancialmente las dinámicas de la ocupación territorial no siempre proyectada, obligan a una respuesta acerca de hasta dónde las instituciones responsables de la formulación y administración de estas figuras son igualmente responsables del ordenamiento territorial de las áreas en donde despliegan su acción y de los impactos que generan fuera de sus límites.

Por ejemplo, los territorios indígenas además de regirse por sus planes de vida, son asunto de las divisiones especializadas del Ministerio de Gobierno. Si esta entidad toma la medida de sanear algunas áreas solapadas con otros grupos poblacionales, ¿será este ministerio quien se haga responsable de situar esta población en otra zona? Como esta nueva zona hace parte de un municipio y este a su vez de un departamento, ¿las provisiones de suelo para la producción y vivienda de las personas 
trasladadas y los soportes de servicios públicos, espacio público, equipamientos y nuevas vías serán gestionadas y financiadas por dicho ministerio? O ¿hasta dónde llegará su responsabilidad?

Además, como la formulación del POTD supone la armonización de las decisiones a nivel departamental con los proyectos de ejecución nacional, es decir que estos proyectos serán incorporados al modelo de ocupación del Plan Departamental, también lo será el seguimiento y evaluación de su ejecución ya que parte de los resultados del modelo de ocupación serán atribuibles a la acción de la Nación. En ese sentido los organismos responsables de la Nación tendrán que reportar el avance de sus proyectos al departamento, el cual deberá integrarlos a su sistema de monitoreo y seguimiento.

Otra integración que plantea dificultades no menores es la de los municipios y sus planes con el Plan departamental, pues este necesita del acoplamiento tanto de su modelo de ocupación a los modelos territoriales producidos por cada municipio, como de sus instrumentos de regulación. Como esta necesaria armonización hace parte de los procesos consensuados de formulación del POTD, pero a su vez de los procesos de seguimiento establecidos en los expedientes municipales, deberán plantearse observatorios departamentales en donde concurran los instrumentos de seguimiento a los planes municipales y recoger los aportes de la experiencia nacional.

\section{RESULTADOS. EL APORTE DE LA EXPERIENCIA NACIONAL}

Como se ha señalado, el POTD es un instrumento nuevo que por lo novedoso aún no tiene unificados los procedimientos, contenidos e instrumentos, ni tampoco los abordajes metodológicos para su formulación y adopción. Hay un cierto número de ejercicios de construcción de directrices departamentales, pero muy pocas experiencias en la formulación de POTD. Los enfoques sobre este instrumento se pueden sintetizar así:

Los ejercicios desarrollados tienen en común la propuesta metodológica de un modelo de ocupación territorial a partir de una visión prospectiva. Este modelo territorial se orienta hacia una articulación regional o nacional que busca la integración intradepartamental, al tiempo que vincula redes de comunicación, procesos productivos y nodos (puertos y aeropuertos) a una propuesta de subregionalización planteada como estrategia diferencial que le permite su integración territorial interdepartamental. Se plantea como un instrumento de iniciativa pública que será insumo para los POT municipales.

Las metodologías incluyen unos escenarios de referencia para el modelo de ocupación, entre los cuales tienen relevancia la revisión de los modelos de ocupación de los municipios de su jurisdicción, el uso intensivo de los Sistemas de Información Geográfica (SIG), por ejemplo en el modelo del Valle del Cauca y un enfoque poblacional como punto de partida, que en el caso del Guaviare apela a proyecciones de largo plazo (2040) para estimar consumos de suelo que contrastan varios escenarios. Otro aspecto destacable de las metodologías utilizadas es el uso de la teoría de las redes para el diagnóstico de la conectividad y movilidad, así como la tendencia a proponer proyectos concurrentes ${ }^{3}$ de impacto regional.

3 Las experiencias han sido prolijas en propuestas de proyectos que vinculan la gestión de varias entidades o varios niveles de planificación, lo cual genera economías de escala y podría facilitar su gestión. 
LÍNEA DE INVESTIGACIÓN: CIUDADES COMPETITIVAS

Los procesos de formulación son intensamente participativos -como en el caso del Guaviare- en la construcción de la visión de desarrollo departamental y ampliamente discutidos sus avances con organizaciones que desarrollan alguna acción al interior, así como en instituciones del nivel nacional, agencias de cooperación internacional y ONG.

En cuanto a los contenidos se observa que los asuntos ambientales, la estructura ecológica principal y la apuesta por la sostenibilidad ocupan gran parte de las preocupaciones, como también las apuestas productivas orientadas a mejorar sus capacidades para la competitividad. Otros temas relevantes son el equilibrio urbano-rural, la relación entre las áreas de carácter ecológico y las construidas, los proyectos estratégicos de servicios públicos y transporte multimodal y la articulación de la red de ciudades mediante modelos jerárquicos (MVCT, 2012).

Las estrategias planteadas buscan consensuar localización de las concentraciones de servicios regionales, definir áreas de administración supramunicipal subordinadas a una subregionalización, empoderar algunos asentamientos a través de la inyección de recursos, dotar al plan de instrumentos para orientar el modelo de ocupación y definir mecanismos de cooperación y concurrencia técnica y financiera. Sin embargo no se observan iniciativas tendientes a crear, suprimir, segregar y agregar territorios municipales, ni a organizar provincias, y pocas, para definir estándares de soportes territoriales y urbanos.

La experiencia en la formulación de directrices departamentales ha permitido llegar a algunos acuerdos en torno a las competencias de ordenamiento territorial de los departamentos, los cuales, de acuerdo con el DNP (2013), se pueden resumir de la siguiente forma:

- Establecer directrices y orientaciones para el ordenamiento de la totalidad o porciones específicas de su territorio con el fin de determinar los escenarios de uso y ocupación del espacio.

- Definir las políticas de asentamientos poblacionales y centros urbanos.

- Orientar la localización de la infraestructura física-social para aprovechar las ventajas competitivas regionales y promover la equidad.

- Integrar y orientar la proyección espacial de los planes sectoriales, municipales y de entidades territoriales indígenas.

- Articular sus estrategias de OT con los planes y actuaciones sobre el territorio, mediante la adopción de POTD.

- Establecer las orientaciones específicas para el OT en los municipios que hacen parte de un área metropolitana.

- Implementar programas de protección especial para la conservación y recuperación del medio ambiente a través de asociaciones de ET.

- Formular proyectos estratégicos de desarrollo territorial que se ejecutarán entre la Nación y las entidades territoriales a través de un contrato plan en el cual se establecerán los aportes y fuentes de financiación.

Estos contenidos implican una desagregación de los temas que atañen a cada departamento en sus propios procesos de ordenamiento, pero algunos de ellos desde ya implican algunas dificultades para adelantarlos: 
Para los POT municipales, las directrices al ser determinantes, es decir, decisiones de mayor jerarquía, suponen la obligatoriedad de su cumplimiento. Pero estas directrices inciden en algunos casos en la reglamentación privada del suelo de competencia estrictamente municipal. Por su parte las orientaciones tienen también un carácter vinculante en la medida que aluden a las instrucciones y procedimientos que garantizan la incorporación de las directrices en el POT. Como se ha descrito, el departamento, al no contar con competencias e instrumentos propios para regular el suelo privado, no puede incidir en las decisiones de ocupación individual directamente con el plan departamental, sino que debe hacerlo a través de los planes municipales. Al insistir en ello, genera conflictos de competencias que lesionan la autonomía municipal y agudiza los conflictos de interés inherentes al ordenamiento.

Con respecto a la desagregación de contenidos, se incluye una variedad de temas como son la estructura ecológica principal, la declaratoria y manejo de los suelos de protección para la conservación ambiental y cultural, la gestión del riesgo y el cambio climático, las categorías de suelo rural, suburbano y de expansión, los instrumentos de planificación rural, el sistema de centros poblados y los sistemas estructurantes, los cuales obligan a precisar los alcances de la intervención de cada nivel de planificación en lo relativo a los ámbitos de pertinencia de acuerdo a sus competencias, escalas de trabajo, complementariedad de las acciones y aplicación de instrumentos de planificación y gestión.

\section{COMENTARIOS}

Este documento ha planteado algunas reflexiones acerca de la formulación de los planes de ordenamiento territoriales departamentales, debido a que su implementación afecta a todos los niveles territoriales. A su vez estas reflexiones dan pie para pensar en una planeación escalar que cubra el conjunto del sistema de planeación nacional.

Los nuevos instrumentos de planeación intermedia se insertan en la órbita departamental, organismo debilitado por tener competencias limitadas en términos de las funciones centrales del ordenamiento territorial. Esta circunstancia haría imperativo el debate sobre su misma existencia como entidad territorial, pero dadas las funciones que mediante la Ley Orgánica de Ordenamiento Territorial le han sido asignadas, se evidencia un fortalecimiento de su papel intermediador y armonizador de los diferentes niveles de planeación.

Las limitaciones de los departamentos con respecto al POTD tienen que ver con la carencia de competencias sobre las funciones vitales de la planeación territorial, la insuficiencia de los instrumentos de gestión territorial para materializar las operaciones resultantes del ejercicio de las competencias que sí poseen; el carácter unidireccional de la intermediación que realizan, las precisiones que necesitan para reducir los conflictos de autonomía con otras entidades, la redundancia de los contenidos y la sincronización de tiempos con otros niveles de planeación, así como la complejidad y ambigüedad de los temas a los cuales debe hacer seguimiento .

Además de las dificultades expresadas y las inherentes a la labor de armonizar los planes que se desarrollan en su jurisdicción, el POTD debe sortear obstáculos que ponen de relieve tres aspectos del ordenamiento territorial sobre los cuales ha de desarrollar su accionar:

- La provisión de lineamientos para la organización del suelo público 
LÍNEA DE INVESTIGACIÓN: CIUDADES COMPETITIVAS

- La formulación de directrices de operación de las cargas generales que definirán un modelo de ocupación departamental y los estándares regionales, además de permitir armonizar los ordenamientos locales para el aprovechamiento del suelo.

- La ejecución programada y coordinada de los sistemas estructurantes para balancear el sistema de ciudades, equilibrar usos, ocupaciones y densidades con el aporte técnico y financiero de proyectos regionales.

Su actuación sobre estos tres ejes de la planificación permitirá poner a prueba su capacidad para modificar las jurisdicciones municipales; liderar y fomentar la asociatividad entre entidades territoriales; crear organismos de gerencia subregionales y supramunicipales; empoderar lugares con macroproyectos, centros industriales y logísticos, zonas francas o generar centralidades con su aporte de equipamientos regionales; y proteger áreas estratégicas para la seguridad alimentaria, las vocaciones, el tratamiento de los conflictos y la riqueza cultural de la Nación.

Al mismo tiempo, permite dar claridad a los contenidos del plan departamental al delimitar su acción frente a la estructura ecológica principal y las reservas para servicios públicos; la macrozonificación del riesgo y de la producción rural, y las consecuentes orientaciones para su manejo; la asignación de especializaciones productivas de acuerdo a la vocación, a las necesidades de producción y al papel de cada zona en una producción competitiva y articulada; las especificaciones de infraestructuras nodales de movilidad regional e interconexión troncal intermunicipal, así como de producción, tratamiento y distribución de servicios públicos domiciliarios, servicios públicos y equipamientos a nivel regional que complementan la actuación nacional y municipal.

No obstante, el progreso de las actuales experiencias de los departamentos en la formulación de directrices y de sus planes de ordenamiento -y especialmente su implementación- será lo que permitirá precisar estos instrumentos y la capacidad de estas entidades territoriales para llevarlos a cabo.

\section{REFERENCIAS}

Boix D. (2003), Redes de Ciudades y Externalidades. Tesis doctoral. Departamento de Economía Aplicada, Universidad Autónoma de Barcelona.

Boisier, S. (2006), Imágenes en el espejo. Aportes a la discusión sobre crecimiento y desarrollo territorial, Puerto de Palos

COT (2016) Propuesta de ACUERDO de la COT. "Por el cual se establecen los criterios, para el proceso de formulación de Directrices y Planes de Ordenamiento Departamental -POD-". Work Paper. Comisión Nacional de Ordenamiento Territorial. Secretaría Técnica Departamento nacional de planeación DNP.

Departamento Nacional de Planeación (2013) lineamientos para adelantar el proceso de Ordenamiento Territorial Departamental. Secretaría Técnica COT Nacional. Comité Especial Interinstitucional. Bogotá. Recuperado de: https://colaboracion.dnp.gov.co/CDT/Desarrollo\%20 Territorial/PF\%20Lineamientos\%20para\%20adelantar\%20proceso\%20OTD\%20\%20Dic\%20 2013.pdf 
DNP. (2003), CONPES 3238, Estrategias para el Fortalecimiento Departamental, agosto 11 de 2003. Imprenta nacional. Bogotá D.C.

Giraldo, C. A (2008) El proceso de planificación en las entidades territoriales: el plan de desarrollo y sus instrumentos para la gestión 2008-2011. Bogotá. DC. Departamento Nacional de Planeación, DNP y Escuela Superior de Administración Pública, ESAP. Imprenta Nacional de Colombia.

Instituto Geográfico Agustín Codazzi (2012). Aportes Del IGAC a la Construcción de la Política Nacional de Ordenamiento Territorial. Working Paper. Subdirección de Geografía y Cartografía. Grupo Interno de Trabajo en Ordenamiento Territorial.

Jonas, A., y K. Ward (2007). Introduction to a Debate on City - Regions: New Geographies of Governance, Democracy and Social Reproduction. International Journal of Urban and Regional Research, 31.1, 169-78

Massiris A. (2010). Ordenamiento Territorial: Experiencias internacionales y desarrollos conceptuales y legales realizados en Colombia. Biblioteca virtual, Biblioteca Luis Angel Arango.

Ministerio de Vivienda, Ciudad y Territorio MVCT (2012) Bases Conceptuales para la Formulación del Ordenamiento Territorial Departamental en el Marco de la LOOT / Ley 1454 De 2011. Working Paper. Viceministerio de Vivienda y Desarrollo Territorial Dirección de Espacio Urbano y Territorial.

Moya G., et al. (1999) La práctica del planeamiento urbanístico. Editorial Síntesis.

Rivera, A. (2009). Análisis del Avance Del Ordenamiento Territorial Departamental en Colombia. Escuela Superior De Administración Pública, ESAP

Sandoval, C. E. (2014) Métodos y aplicaciones de la planificación regional y local en América Latina. Serie desarrollo territorial $N^{\circ}$ 17. CEPAL. Publicación de las Naciones Unidas. Santiago de Chile.

SENPLADES, CONCOPE, AME, CONAJUPARE (2010). Lineamientos para la planificación del desarrollo y el ordenamiento territorial. Estrategias para el fortalecimiento del Sistema Nacional Descentralizado de Planificación Participativa. Quito. Ecuador. Secretaría Nacional de Planificación y Desarrollo y el Programa ART/PNUD. 